\title{
Tensiones identitarias y discursos conmemorativos: los ítalo-uruguayos filofascistas ante las fiestas cívicas de sus dos patrias (1918-1941)
}

\author{
Identity Tensions and Commemorative Speeches: \\ the Italo-Uruguayan Filofascists before the Civic \\ Celebrations of their Two Homelands (1918-1941)
}

\author{
Juan Andrés Bresciano Lacava \\ ORCID iD: http://orcid.org/0000-0001-8017-4446 \\ Universidad de la República, Uruguay
}

En el período interbélico, la difusión del fascismo en la comunidad ítalo-uruguaya tensiona la lealtad que muestran los migrantes hacia la sociedad de procedencia y la sociedad receptora. Tal tensión varía como resultado de los contextos políticos cambiantes de ambas naciones y se refleja en la prensa del período, particularmente en el semanario L'Italiano, ya que sus discursos conmemorativos sobre las fiestas cívicas de las dos patrias buscan conciliar la identidad italiana y la uruguaya en la recordación de eventos que aluden a los pasados de los dos países.

Palabras Clave: Inmigración; Italia; Uruguay; Fascismo; Fiestas Cívicas; Identidades.

In the interwar period, the spread of fascism in the Italo-Uruguayan community stresses the loyalty shown by migrants to the society of origin and the host society. Such tension varies as a result of the changing political contexts of both nations, and it is reflected in the press of the period, particularly in the weekly L'Italiano, since its speeches, commemorating the civic celebrations of the two countries, seek to reconcile the Italian and Uruguayan identity in the remembrance of events that allude to the pasts of one country and the other.

KEYwords: Immigration; Italy; Uruguay; Fascism; Civic Celebrations; Identities.

Copyright: (C) 2019 CSIC. Este es un artículo de acceso abierto distribuido bajo los términos de la licencia de uso y distribución Creative Commons Reconocimiento 4.0 Internacional (CC BY 4.0). 


\section{Introducción}

Todo movimiento migratorio genera complejas relaciones entre la colectividad migrante, la sociedad de procedencia y la sociedad receptora. De hecho, entre los inmigrantes suele desarrollarse un doble sentimiento de pertenencia que se plasma en una identidad colectiva dual. A veces, un compromiso ideológico (ya sea con una corriente política de la sociedad de partida o de la sociedad de arribo) puede tensionar esa identidad al punto de comprometer el sentimiento de pertenencia hacia una de las dos sociedades. Tal es el efecto que produce — directa o indirectamente_ las simpatías por el régimen fascista entre algunos integrantes de la comunidad ítalo-uruguaya durante el período interbélico.

Promovido por partidarios locales de las más variadas extracciones socioeconómicas, el fascismo arraiga tempranamente en algunas instituciones de esa colectividad al tiempo que desata resistencias. Entre los ítalo-uruguayos que se adhieren al fascismo, se entremezclan las convicciones sinceras de algunos, el oficialismo oportunista de otros y el nacionalismo tradicional de muchos. Su compromiso varía durante el período referido: resulta tímido en los años veinte, decidido a principios de los treinta, vigoroso durante la Segunda Guerra Ítalo-Etíope, exultante hasta el estallido de la Segunda Guerra Mundial, e insignificante a partir de que Uruguay rompe relaciones diplomáticas con las potencias del Eje. Debe señalarse que en ese proceso de difusión del fascismo cumple un papel fundamental la representación diplomática italiana. Al igual que las legaciones establecidas en otros países, ${ }^{1}$ la de Montevideo ejerce un control creciente sobre los espacios de sociabilidad y sobre las instituciones educativas de la colectividad, al tiempo que promueve actividades culturales que tienden a identificar a Italia con el fascismo.

Si bien en Uruguay el peso específico de los filofascistas dentro de la población migrante y sus descendientes es objeto de debate, algunas cifras (las de los combatientes en la Segunda Guerra Ítalo-Etíope ${ }^{2}$ y las de los donantes de anillos matrimoniales para financiar el conflicto) ${ }^{3}$ permiten estimar un mínimo de adherentes. Lo mismo puede afirmarse de las fotografías que registran la presencia de cientos de simpatizantes en diversos

1 Franzina y Sanfilippo, 2003; Domínguez, 2012.

2 «Elenco dei Volontari per l'Africa Orientale partiti da Montevideo», L'Italiano, XXVI, 1209-1210, 8-15 de diciembre de 1935, 2.

3 «Oro alla Patria», L'Italiano, XXVII, 1212, 19 de enero de 1936, 1. 
actos públicos. ${ }^{4}$ Por otra parte, el surgimiento en el medio local de entidades vinculadas al régimen fascista (como el Fascio de Montevideo o la sección local de la Opera Nazionale Dopolavoro), ${ }^{5}$ así como la fascistización de las dirigencias de las asociaciones de la colectividad y de la propia Scuola Italiana,${ }^{6}$ permiten ponderar cualitativamente las adhesiones.

Sea cual fuere su número y su gravitación en el seno de la sociedad receptora, los filofascistas ítalo-uruguayos deben enfrentar, a lo largo de dos décadas, el desafío de conciliar su doble pertenencia en una identidad dual que entrelaza dos historias. El modo en que se integran pasados y presentes, de manera armónica en ciertos momentos y de un modo forzado en otros, da cuenta de las transformaciones políticas, económicas, sociales y culturales que afectan tanto a Uruguay como a Italia durante la entreguerra.

El presente artículo se propone analizar, a partir de la consideración de esas transformaciones, las diversas formas en que se resuelve la tensión identitaria que provoca el compromiso patriótico con la sociedad de procedencia y la sociedad de arribo, en el caso de los italianos inmigrantes comprometidos con el fascismo. Para ello se considerarán los intentos de armonización de ambas lealtades a través de aquellas celebraciones en las que los ítalo-uruguayos conmemoran hechos destacados de las historias de sus dos patrias, ya sea que esos hechos se celebren como feriados nacionales, jornadas festivas, fiestas consuetudinarias o solemnidades civiles.

La rememoración periódica de acontecimientos del pasado, consagrada por los Estados o impulsada por las sociedades o por algunos de los grupos que las integran, configura uno de los factores que, en el plano simbólico, contribuyen a cimentar y consolidar las identidades colectivas. La determinación de los hechos que se celebran, su consagración por una tradición existente, su reconocimiento por una resolución jurídica o su imposición por la voluntad de los gobernantes obedecen a complejas dinámicas en las que inciden todos aquellos actores que generan discursos con respecto al pasado, incluyendo a los historiadores. Estas festividades pueden concebirse como un mecanismo que propende a la reproducción de las identidades construidas, pero también puede entenderse como un instrumento capaz de resignificarlas. De hecho, durante el período interbélico los días festivos de carácter nacional varían sustancialmente en Uruguay y en Italia. En tal sentido, cabe señalar que la eliminación por ley de unos y la incorporación

4 La prensa ítalo-uruguaya del período proporciona un material abundante al respecto.

5 Bresciano, 2016.

6 Bresciano, 2017. 
de otros, así como la integración de ciertos festejos no oficiales en el transcurso de la entreguerra, suscitan polémicas que desafían el sentimiento identitario ítalo-uruguayo. Esos desafíos que generan las nuevas y viejas efemérides de ambas patrias, se reflejan en los discursos que se pronuncian durante sus celebraciones, en la realización de los actos que las evocan y en la producción iconográfica que las simboliza.

Para abordar sistemáticamente estas tres expresiones, las fuentes hemerográficas ofrecen un material de gran valor heurístico. Históricamente, la prensa de inmigración se presenta como un medio de expresión y de reafirmación de un grupo de hombres y mujeres que, procedentes de otra sociedad, aspiran a integrarse a la sociedad que los acoge, manteniendo las tradiciones del ámbito del que provienen. Las publicaciones periódicas (editadas, en muchos casos, en la lengua del país de origen) no solo refieren las noticas que atañen a la colectividad migrante, sino que fomentan la compra de bienes que producen sus integrantes, promueven la participación de estos últimos en las asociaciones locales e impulsan el interés conjunto por saber lo que acontece en la «patria lejana». También generan discursos que, vinculando el pasado y el presente mediante una interpretación ideológica más o menos explícita, inciden en la conformación de la identidad colectiva del grupo migrante.

La prensa ítalo-uruguaya durante el período interbélico constituye un buen ejemplo de ello. ${ }^{7}$ En esos años surgen varios órganos de prensa que reflexionan sobre la italianidad a partir de los lineamientos doctrinales del fascismo. ${ }^{8}$ Ninguno de ellos, sin embargo, tiene la trayectoria y la proyección de L'Italiano (1912-1941), ya que, bajo la dirección de Giuseppe Nigro, este semanario se convierte en un temprano defensor de las ideas de Mussolini. Desde una perspectiva hermenéutica, L'Italiano resulta relevante porque, además de reproducir las alocuciones pronunciadas con motivo de las fiestas cívicas italianas y uruguayas, crea sus propios discursos celebratorios. A través del registro fotográfico presenta, a su vez, los escenarios en que se efectúan los actos conmemorativos y publica ilustraciones artísticas que simbolizan los hechos rememorados. Por lo tanto, el análisis de sus textos y de sus imágenes resulta la opción metodológica idónea para cumplir con el objetivo que se propone este trabajo.

7 Sergi, 2014.

8 Por orden alfabético: Corriere d'Italia (1932-1935); Fascismo (1933); Fiamma Italica (1932-1933); Il Dopolavorista (1934); Il Messagero d'Italia (1930); Il Piave (1924-1925); Il Piccolo (1926); Italia Nova (1926); L'Era Nuova (1925); La Verità (1925); La Voce d'Italia (1926); Marcia su Roma (1924-1926); SENATUS POPULUS QUE ROMANUS (1936-1938). 


\section{Tiempos de transición: la simpatía por el fascismo naciente en el Uruguay de tradición garibaldina (1918-1925)}

A principios de los años veinte, Uruguay se presenta como una sociedad próspera, capaz de atraer (aunque con menor intensidad) a la inmigración europea que, desde la segunda mitad del siglo XIX, afluye a sus costas. En ese entonces, el país crece económicamente a partir de un modelo agroexportador que estimula una industrialización incipiente. La población, mayoritariamente urbana y alfabetizada, desarrolla una intensa vida cultural, cuyo principal referente es Europa Occidental. En el plano político, la reforma constitucional de 1918 consagra el voto masculino universal e institucionaliza la democracia política, luego de que diversas reformas sociales a principios de siglo instaurasen en Uruguay el primer Estado benefactor de la región. Con un Poder Ejecutivo bicéfalo, integrado por el presidente de la República y por el Consejo Nacional de Administración, y con un Poder Legislativo que se renueva parcialmente cada dos años, la participación política de la ciudadanía alimenta una cultura democrática que será uno de los signos distintivo del país. La reforma constitucional supone, además, la culminación del largo y conflictivo proceso de secularización que separa definitivamente la Iglesia del Estado. ${ }^{9}$

En ese Uruguay moderno, la colectividad italiana tiene una trayectoria destacada que se remonta a la presencia de Garibaldi y de sus legionarios en los años cruciales de la Guerra Grande. Durante la segunda mitad del siglo XIX, asociaciones de socorro mutuo, organizaciones recreativas y deportivas, así como clubes sociales, nuclean a sus integrantes no solo en Montevideo sino en casi todas las ciudades del país. ${ }^{10}$ Para principios del siglo XX, los ítalo-uruguayos conforman una colectividad en la que coexisten varias generaciones integradas política, económica, social y culturalmente al país que la acoge.

Esa colectividad demuestra una preocupación manifiesta por la suerte del país del que procede, durante el transcurso de la Primera Guerra Mundial. De hecho, algunos de los inmigrantes y de sus descendientes deciden partir como voluntarios para combatir en las filas del Regio Esercito. El desenlace del conflicto, con el triunfo de las fuerzas italianas sobre las austro-húngaras en la batalla de Vittorio Veneto, motiva numerosos festejos que alimentan en algunos un nacionalismo conservador. L'Italiano, fuente

9 Véase Caetano y Geymonat, 1997, tomo 1.

10 Véase Devoto, 1993; Adamo, 1999. 
primaria para este estudio, canaliza ese nacionalismo a través de una producción discursiva triunfalista, así como de una iconografía alegórica muy efectiva a la hora de transmitir ciertos mensajes. A través de sus páginas, fomenta un clima de exacerbación patriótica que disimula las frustraciones de la inmediata posguerra. Por ello, se muestra entusiasta cuando se produce la Marcha sobre Roma y se forma un nuevo gobierno presidido por Benito Mussolini en octubre de 1922. De manera gradual, ese entusiasmo se transforma en adhesión, ya que en los años siguientes ese gobierno sienta las bases de un nuevo régimen inspirado en una ideología que el semanario no duda en calificar de renovadora.

En un tiempo en el que Uruguay consolida su democracia y en el que Italia transita hacia el totalitarismo, L'Italiano comprende bien el papel articulador que cumple la conmemoración de aquellas fiestas cívicas que instrumentalizan los pasados de ambos países y los relacionan con los compromisos políticos del presente. Por ello, en los años veinte promueve dos celebraciones: la del 24 de mayo de 1915 (la intervención de Italia en el conflicto) y la del 4 de noviembre de 1918 (la culminación de la batalla de Vittorio Veneto). Estos dos eventos se suman a dos fechas históricas que son fiestas nacionales del Reino de Italia antes del ascenso del fascismo: el primer domingo de marzo (la celebración de la unidad de Italia y de la aprobación del Estatuto Albertino, constitución otorgada por los Saboya el 4 de marzo de 1848) y el 20 de septiembre de 1870 (el ingreso de las tropas italianas a Roma).

La relación que se establece entre estos cuatro hechos, en términos de pasado reciente y de pasado distante, resulta peculiar. A principios de la década del veinte, hay un número minúsculo de italianos establecidos en el Uruguay que recuerdan cuándo se firmó el Estatuto Albertino. Existe además un grupo pequeño de italianos que por su edad todavía tienen presente el ingreso de las tropas italianas en Roma. A ellos se agrega el grupo mayoritario de los que, habiendo nacido luego de que se produjeran esos hechos, siguieron a través de la prensa el desarrollo de la Primera Guerra Mundial. En conclusión, de las cuatro fechas celebradas, la primera, salvo algunas excepciones, escapa al campo de la historia vivida; la segunda forma parte de esa historia vivida, al menos para un grupo pequeño de inmigrantes, mientras que las dos restantes signan la historia reciente de la mayoría de los ítalo-uruguayos.

La constatación de que tres de los cuatro hechos conmemorados responden a una historia vivida, y que dos de ellos se vinculan con un pasado 
reciente, introduce un factor relevante para el análisis. Cuando los eventos que se celebran son previos a la historia vivida por la mayoría de los integrantes de una comunidad, las formas de celebración ya se encuentran claramente establecidas y sus contenidos definen una rutina celebratoria. Cuando los hechos que se conmemoran son parte de la historia vivida por algunos de los integrantes de una comunidad, alimentan vivencias personales que gravitan históricamente con un peso específico. Finalmente, cuando los hechos se insertan en el campo de la historia reciente o de la historia inmediata, las formas de conmemorarlos se hallan en proceso de constitución, y las vivencias personales con relación a ellos otorgan una dinámica mucho más emotiva a las celebraciones. ${ }^{11}$

El segundo factor a considerar consiste en el modo en que evoluciona la percepción de los hechos celebrados, cuando se transforma la valoración de sus repercusiones históricas. L'Italiano comunica entusiastamente la culminación victoriosa de la batalla de Vittorio Veneto apenas llega la noticia. Al poco tiempo, insta a celebrarla como expresión del fin del conflicto y del triunfo de Italia en la guerra. ${ }^{12}$ Esta celebración se repite en los años siguientes. ${ }^{13}$ A partir de entonces, la conmemoración del evento se transforma en una afirmación identitaria particularmente vigorosa, ya que vincula pasado inmediato y presente, en un lazo que se fortalece con el transcurso de los años. ${ }^{14}$ Una alegoría iconográfica publicada por el semanario resalta el sentido del hecho, transformándolo en un símbolo de renovación triunfal (figura 1). En esa alegoría, una figura femenina coronada (representación del Reino de Italia) reposa sobre un cuadro que contiene «el parte de la victoria», comunicado por el general Armando Díaz. Junto al cuadro se encuentra la bandera italiana y los fascios lictorios (que en este contexto se refieren a la unidad italiana y no al incipiente movimiento fascista).

En los primeros años de la década del veinte, la celebración de la victoria de Vittorio Veneto motiva, necesariamente, una resignificación del inicio del proceso que conduce a ella. Por ello, L'Italiano insta a conmemorar

11 Para profundizar en este tema, véase Aróstegui, 2004; Lowenthal, 1998.

12 «Sopra l'ultima cresta delle Alpi nostre, innanzi alle rovine dell'Impero degli Asburgo, l'Italia pone il marmo a Caio Mario e a Giuseppe Garibaldi col motto: "Stranieri a dietro" [indietro?]. In tutto l'arco dell'adriatica marina, la Vittoria italica bandisce: "O popoli! Italia qui giunse vendicando il suo nome e il diritto"», L'Italiano, VII, 337, 10 de noviembre de 1918, 1.

13 «Nel secondo anniversario di Vittorio Veneto», L'Italiano, IX, 439-440, 31 de octubre-7 de noviembre de 1920, 1 .

14 «Nel giorno dell'apoteosi della nostra vittoria», L'Italiano, X, 490-491, 29 de octubre-5 de noviembre de $1921,2$. 


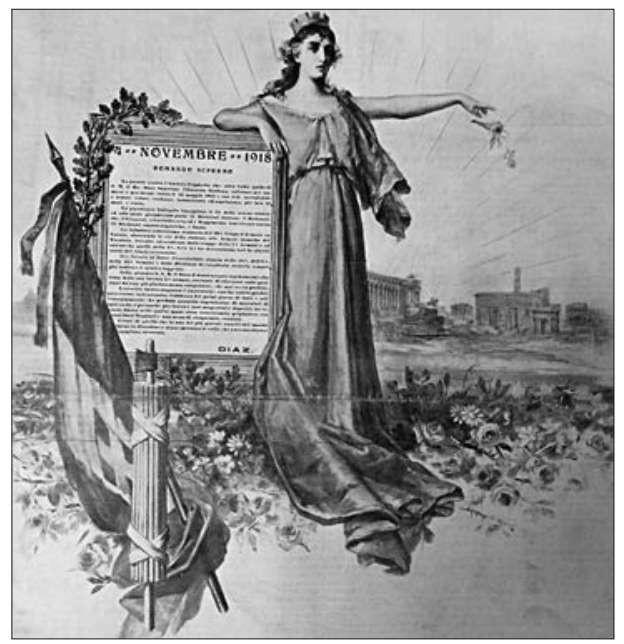

Figura 1. Alegoría del 4 de noviembre. L'Italiano, XIV, 592-593, 28 de octubre-4 de noviembre de 1923, 1.

la Intervención. Según su perspectiva, la actuación de Italia en la Primera Guerra Mundial, desde la decisión de participar en el conflicto hasta la victoria final, canaliza una fuerza transformadora que trasciende al propio país. Como prueba de ello, cita estas palabras de Pedro Manini Ríos, ítalo-uruguayo de una extensa trayectoria política:

La entrada de Italia en la guerra, el 24 de mayo de 1915, significó la salvación del frente aliado; la victoria italiana, el 4 de noviembre de 1918, fue la jornada augural del triunfo definitivo para la causa de la Humanidad. ${ }^{15}$

A partir de tal constatación, el semanario planteó una relectura de las fechas celebradas tradicionalmente, en especial la del 20 de septiembre: el ingreso de las tropas italianas en Roma constituye, entonces, el fin de una Italia subyugada y el principio de su ascenso como potencia. Este último proceso alcanza su paroxismo con la intervención de Italia en la conflagración mundial y su ulterior victoria. La asociación entre estas tres fechas se simboliza en una ilustración que L'Italiano publica en septiembre de 1923. ${ }^{16}$ Se trata de una composición en la que predomina una efigie femenina, representación de la diosa Roma, a cuyos lados se despliegan sendas banderas italianas; debajo de ella se destaca una reproducción del Monumento

15 «S. E. l'on. Pietro Manini Ríos, ex Ministro degli Esteri dell'Uruguay», L'Italiano, XV, 695-696, 1-8 de noviembre de 1925, 2.

16 «el 53॰ anniversario del XX Settembre», L'Italiano, XIV, 586-587, 16-23 de setiembre de 1923,1 . 
Nacional a Vittorio Emanuele II; en el margen superior se hace referencia al 20 de septiembre, mientras que las dos banderas que acompañan a la diosa mencionan dos fechas relacionadas (el 24 de mayo y el 3 de noviembre, ${ }^{17}$ respectivamente); a su vez, al pie de la ilustración aparece la loba capitolina (figura 2). Esta alegoría transmite un mensaje claro: la Roma eterna, que resurge con la unificación italiana, se proyecta con firmeza hacia el futuro al emerger triunfante de la Primera Guerra Mundial.

Las celebraciones cívicas que instituye el régimen fascista, por otra parte, son fielmente conmemoradas. Así sucede con el 21 de abril, el Natale di Roma. Esta fecha se convierte a partir de 1924 en la Festa del Lavoro, que sustituye al Día de los Trabajadores, evento reivindicativo de las luchas de la clase obrera y de sus mártires, celebrado el 1. ${ }^{\circ}$ de mayo.

Según L'Italiano, en el Natale di Roma-Festa del Lavoro se exalta el trabajo, no como manifestación de una tradición combativa clasista e internacional, sino como expresión de la laboriosidad de un pueblo que fue civilizador en el pasado y que se halla destinado a un fin igualmente trascendente en el presente. Así lo manifiesta una ilustración que reproduce el semanario, en la que figura un dibujo de la loba capitolina presidido por el retrato del rey; debajo, junto al escudo de los Saboya, se halla un

Figura 2. Alegoría que relaciona distintas fiestas cívicas. L'Italiano, XIV, 586-587, 16-23 de septiembre de 1923, 1.

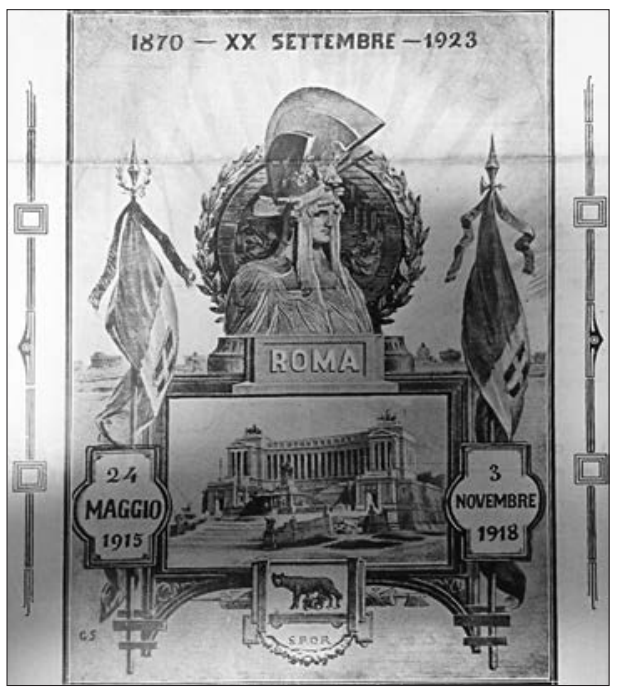

17 En algunas ocasiones, L'Italiano menciona el 3 de noviembre como la finalización de la batalla de Vittorio Veneto, aunque oficialmente sea el 4 de noviembre. 


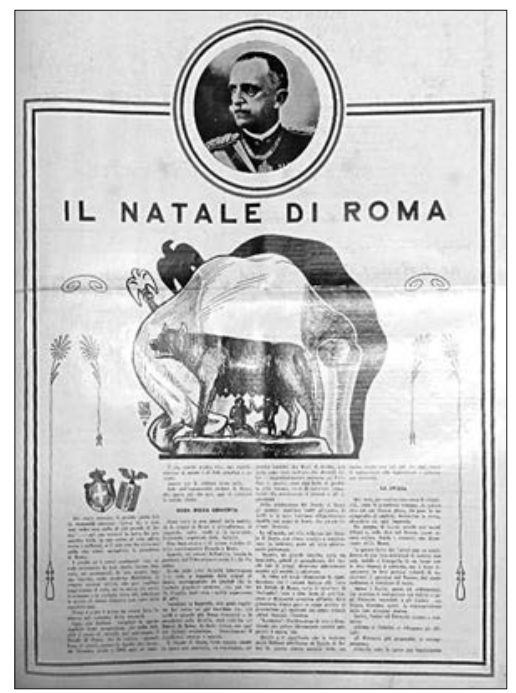

Figura 3. «Il Natale di Roma».

L'Italiano, XIX, 872-873, 21-28 de abril de 1929, 1.

estandarte con el águila romana; la unión de ambos simboliza la conjunción de dos «pasados gloriosos» que gravitan en un presente de transformaciones (figura 3).

El tercer aspecto a destacar radica en el significado que adquiere la conmemoración de ciertas fechas cívicas uruguayas a partir del fervor nacionalista que inspira la culminación de la Primera Guerra Mundial. Al respecto, cabe señalar que en 1915 un decreto del presidente Feliciano Viera establece el 20 de septiembre como día feriado; en 1917 el Poder Legislativo declara esa fecha feriado nacional, mientras que en 1919, con la aprobación de la ley de feriados nacionales, ${ }^{18}$ el 20 de septiembre se transforma en el Día de Italia.

La transformación de esa fecha en fiesta patriótica uruguaya se percibe, desde la perspectiva de L'Italiano, como un reconocimiento a las

18 La ley n. 6.997 establecía lo siguiente: «Desígnanse los días $1 .^{\circ}$ de enero (Año Nuevo), 6 de enero (Día de los Niños), 28 de febrero (Grito de Asencio), 19 de abril (Día de los Treinta y Tres), 1. ${ }^{\circ}$ de mayo (Día de los Trabajadores), 2 de mayo (Día de España), 18 de mayo (Batalla de la Piedras), 25 de mayo (Día de América), 19 de junio (Día de Artigas), 4 de julio (Día de la democracia), 14 de julio (Día de la Humanidad), 18 de julio (Jura de la Constitución), 25 de agosto (Independencia Nacional), 20 de setiembre (Día de Italia), 21 de setiembre (Cabildo Abierto), 12 de octubre (Día de la Raza), 8 de diciembre (Día de las Playas) y 25 diciembre (Fiesta de la Familia), feriados permanentes. Decrétase la paralización del trabajo el 2 de noviembre destinado a la conmemoración de los muertos, destínanse días para la fiesta de Carnaval y declárase feriada la sexta semana siguiente a Carnaval con el nombre de Semana de Turismo». Centro de Información Oficial, Normativa y Avisos Legales del Uruguay, en línea, http://www.impo.com.uy/bases/leyes/6997-1919 [Consultado: 15/03/2018]. 
contribuciones de los inmigrantes peninsulares y a la grandeza de Italia, madre de esa latinidad de la que la cultura uruguaya es tributaria. Lo cierto es que el Día de Italia se celebra en el Uruguay de ese entonces como un triunfo de secularización, ya que el 20 de septiembre no solo supone la culminación del proceso de la unificación italiana sino el fin del poder territorial de la Iglesia católica. Minimizando este aspecto, en uno de sus artículos L'Italiano reproduce una expresión de agradecimiento al Parlamento uruguayo por haber instituido ese día como feriado nacional:

\author{
ALL'ONOREBOLE CAMERA \\ DEI DEPUTTATI DELL'URUGUAY \\ CHE DICHIARANDO FESTA DELLA REPUBBLICA \\ IL XX DI SETTEMBRE \\ VOLLE FIERAMENTE RATIFICARE \\ L'UNIVERSALITÀ DEL FATTO \\ CHE DIEDEALL'ITALIA LA SUA CAPITALE \\ ALL'UMANITÀ LA LIBERTÀ DI CONOSCENZA \\ LA COLLETTIVITÀ ITALIANA \\ RICONOSCENTE, ESULTANTE \\ PER IL NUOVO PEGNO D'AMICIZIA \\ DELLA GENEROSA PATRIA DI ARTIGAS \\ ALLA PATRIA DI GARIBALDI \\ PUGNANTE IN DIFESA DEL DIRITTO ITÁLICO \\ E DELLA CIVILTÀ MONDIALE \\ XX SETTEMBRE MCMXVIII. ${ }^{19}$
}

Una apreciación similar desarrolla el semanario con respecto al significado del feriado uruguayo del Día de la Raza (12 de octubre), que se asocia con el culto a la hispanidad. Declara al respecto que la hispanidad es una de las tantas hijas de la latinidad y que, por tal motivo, reafirmar la hispanidad no es otra cosa que valorizar la latinidad de la que procede. Considera, además, que el protagonista del Día de la Raza, Cristóbal Colón, es el genio italiano que abre a España las puertas de América y que hace posible que la hispanidad nazca. ${ }^{20}$ Por lo tanto, la hispanidad le debe doblemente a Italia su razón de ser. Desde una perspectiva actual, los múltiples anacronismos contenidos en tales afirmaciones pueden resultan transparentes, pero no lo eran a principios de los años veinte, ni siquiera para aquellos que no sentían simpatía por el Día de la Raza.

19 «XX Settembre 1919», L'Italiano, VIII, 381, 20 de setiembre de 1919, 1.

20 «1492-12 Ottobre-1922», L'Italiano, XII, 538, 8 de octubre de 1922, 1. 
La tercera fecha a referir, la más significativa para la sociedad receptora, es la del Día de la Independencia (25 de agosto), la única a la que L'Italiano siempre alude. Resulta interesante destacar la polémica que se desata en el Parlamento uruguayo a partir de la creación de una comisión que tiene como objeto determinar la fecha del primer centenario de la independencia nacional. ${ }^{21}$ De hecho, se plantean proyectos contrapuestos: el que se pronuncia por el 25 de agosto de 1825, Declaratoria de la Florida, y el que lo hace por el 18 de julio de 1830, Jura de la Constitución. En esta discusión prevalece el primero y se acepta oficialmente el 25 de agosto como el Día de la Independencia. Más allá de las controversias historiográficas que se plantean durante la polémica, L'Italiano apela a la celebración de esta fecha para resaltar los lazos que unen a Italia y a Uruguay. ${ }^{22}$ La hermandad entre ambos países encuentra su expresión simbólica en una composición fotográfica que publica L'Italiano con motivo del 25 de agosto de 1918, en la que dos jóvenes estudiantes de la Scuola Italiana representan a la monarquía italiana y a la república uruguaya con atuendos evocativos: una luce una corona y la cruz de los Saboya en su pecho, mientras una capa la cubre; la otra lleva el gorro frigio y viste una túnica antigua (figura 4).

Solo en una ocasión la conmemoración del 18 de julio encuentra eco en las páginas del semanario: cuando se cumple el primer centenario de la Jura de la Constitución, en 1930. Con motivo de tal centenario, aparece un número especial en el que se enaltece a la sociedad y a la cultura uruguayas, como una expresión promisoria de la savia latina (figura 5).

El último aspecto a analizar se refiere a la conmemoración de aniversarios especiales. El cincuentenario del 20 de septiembre, celebrado en $1920,{ }^{23}$ se destaca por la magnitud de los festejos que promueven las colectividades italianas en cada ciudad del país, alentadas por la reciente consagración de esa fecha como el Día de Italia. En 1921 se cumplen seiscientos años de la muerte de Dante Alighieri y esta especial ocasión conjuga tres formas celebratorias. ${ }^{24}$ La primera vincula el recuerdo del «poeta nacional»

21 Véase Real de Azúa, 1990, 227-242.

22 «1825-25 de agosto-1918. Italia ed Uruguay», L'Italiano, VII, 325-326, 18-25 de agosto de 1918,3 .

23 «La collettività italiana nell'Uruguay, degna d'Italia per opere di patriottismo e di umanitá, ha compiuto l'apoteosi dei suoi eroi, ha esaltato la sua Grande Madre, nel XX Settembre 1920, Cinquentenario di Roma Capitale», L'Italiano, IX, 434, 20 de septiembre de 1920, 1.

24 «Il sesto centenario della morte di Dante viene a ricordare a tutti gli italiani fuori della patria, l'obligo loro assoluto a cooperare con ogni forza a l'espansione delle energie nazionali», L'Italiano, X, 484, 11 de septiembre de 1921,1 . 
Figura 4. Alegoría de la fraternidad ítalouruguaya. L'Italiano, VII, 324, 11 de agosto de 1918,3 .

FIGURA 5. «Omaggio all’Uruguay», Portada del número especial. L'Italiano, XX, 935-937, 13-17 de julio de 1930.
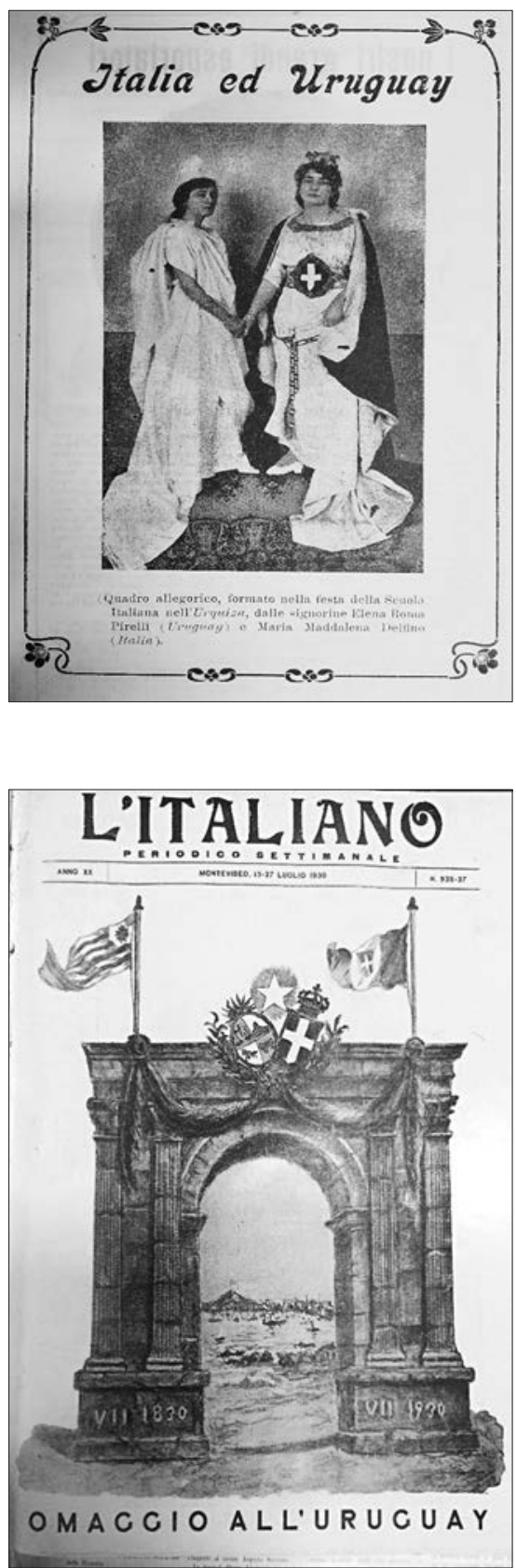
con la rememoración de los ítalo-uruguayos caídos durante la Primera Guerra Mundial; precisamente, el 20 de septiembre de 1921 se inaugura en el Hospital Italiano un monumento que exhibe sus nombres. La segunda consiste en el obsequio de un busto de Dante al Ateneo de Montevideo, acto al que asisten destacadas figuras políticas. ${ }^{25} \mathrm{La}$ tercera celebración se realiza el 25 de septiembre en el Teatro Solís, con un evento musical en el que se interpretan obras de compositores italianos. Durante este evento, que reúne a autoridades nacionales e integrantes del cuerpo diplomático, lee un discurso conmemorativo Emilio Frugoni, destacado intelectual y político ítalo-uruguayo, fundador del Partido Socialista del Uruguay. ${ }^{26}$

Dado que el centenario de la independencia del Uruguay coincide con el vigésimo quinto aniversario de la entronización de Vittorio Emanuele III, ${ }^{27}$ ambas conmemoraciones generan producciones discursivas y simbólicas particularmente significativas. Con motivo del centenario de la independencia, representantes de L'Italiano le entregan un escudo como obsequio a José Serrato, presidente del Uruguay y primer ítalo-descendiente que cumple esa función. ${ }^{28} \mathrm{~A}$ su vez, con motivo del jubileo del reinado de Vittorio Emmanuel III, Giuseppe Nigro, en nombre del semanario, envía una carta de felicitación al monarca. ${ }^{29}$

\section{Tiempos de tensión: la lealtad hacia el Rey y el Duce en el Uruguay republicano y democrático (1926-1932)}

Mientras la democracia uruguaya continúa fortaleciéndose, Italia, bajo el gobierno de Mussolini, se encamina hacia la instauración de una dictadura. En el bienio 1925-1926 se aprueban las leyes fascistísimas que ponen fin a los remanentes del Estado liberal y democrático. Desde el 24 de diciembre de 1925, Mussolini ya no es el presidente del Consejo de Ministros de una monarquía parlamentaria, sino jefe de Gobierno y primer ministro secretario de Estado, solo responsable ante el rey de un país que se

25 «La grandezza d'Italia celebrata in Montevideo. XX Settembre nel culto di Dante, nel ricordo dei caduti», L'Italiano, X, 485, 20 de septiembre de 1921, 1.

26 «La serata dantesca nel "Solís"», L'Italiano, X, 486, 2 de octubre de 1921, 2.

27 «L'Italiano e gli italiani nell'Uruguay alla Maestà del Rè d'Italia Vittorio Emanuele III nel $25^{\circ}$ anniversario del suo glorioso regno», L'Italiano, XV, 682-684, 11 de agosto de 1925, 1.

28 «L'omaggio degli italiani a S. E. Serrato», L'Italiano, XV, 686, 23 de agosto de 1925, 1.

29 «A S.M. Vittorio Emanuele III, Re d'Italia», L'Italiano, XV, 685, 2-9-16 de agosto de $1925,1$. 
autodefine como totalitario, fascista y corporativista. A partir de entonces deja de ser un simple gobernante para convertirse en el Duce de la Nueva Italia.

Este desarrollo de la situación política en la península tiene un efecto perceptible en el plano de la producción discursiva y simbólica de L'Italiano. En lo inmediato, se manifiesta a través de cinco transformaciones que afectan la conmemoración de hechos históricos recientes para ese entonces.

La primera consiste en la celebración de dos natalicios: el del Rey y el del Duce. En el período anterior, la participación victoriosa de Italia en la Primera Guerra Mundial fomentó el culto al rey soldado entre los nacionalistas conservadores, a tal punto que, en los años posteriores al fin del conflicto, el semanario celebraba con entusiasmo el cumpleaños del monarca (11 de noviembre).$^{30}$ En este período, la consolidación del Estado fascista motiva una nueva efeméride que se transforma en celebración no oficial: la del natalicio de Mussolini (29 de julio). El semanario justifica tal celebración en razón del papel salvador que le otorga al gobernante italiano, al que compara con las grandes figuras del Risorgimento, igualando su «obra» a la de ellos:

Il Duce compie oggi quaranta cinque anni. È introno a lui, fidente appassionata, devota, tutta l'Italia che Egli ha fatto di vent'anni. È quell'Italia che quando era schiava, gli Apostoli del Risorgimento gridarono che poteva esser libera, ed essa trovò in sè le forze per liberarsi; è l'Italia miserabile e meschina del 'piedi di casa' alla quale il Poeta insegnò che essa era invece 'il fiore di tutte le stirpi, l'aroma di tutta la terra', ed essa inebriata, si lanciò nella impresa libica e poco dopo osò di affrontare, di abbattere, di distruggere il formidabile Impero austo-ungarico; è infine, l'Italia del dopo guerra che si disfaceva come un corpo in cancrena perché era convinta di essere inesorabilmente malata, ed alla quale il Grande Taumaturgo Benito Mussolini disse la parola magica: «Fascismo». ${ }^{31}$

De este modo, entre los monárquicos filofascistas de la colectividad ítalo-uruguaya se consolida el culto dual al Rey y al Duce. La intensidad con la que se manifiesta este culto demuestra que se trata de una doble adhesión y una doble lealtad: a la monarquía y a la dinastía de Saboya, por un lado, y al régimen fascista y a su líder, por otro. Se trata de un hecho singular, ya que no todos los fascistas tienen simpatías por la monarquía, ni todos los monárquicos aceptan de buena gana el fascismo.

30 Véase a modo de ejemplo: «Per il natalizio del Re. I ricevimenti nella R. Legazione», L'Italiano, XXI, 1002, 15 de noviembre de 1931, 1.

31 «Il compleanno del Duce», L'Italiano, XVI, 834, 29 de julio de 1928, 1. 
La segunda transformación radica en los festejos, promovidos por L'Italiano, de dos hechos recientes para ese entonces: la Marcha sobre Roma (28 de octubre de 1922) y la fundación de los Fasci di Combattimento (23 de marzo de 1919). El orden cronológico en que el semanario incorpora estas celebraciones es exactamente el referido: la valoración de la Marcha sobre Roma, instancia que conduce al surgimiento del régimen fascista, motiva la consagración como fecha histórica del nacimiento de los Fasci di Combattimento, ${ }^{32}$ del mismo modo que en el período anterior la conmemoración del triunfo de Vittorio Veneto condujo, posteriormente, a la reivindicación de la Intervención. El 28 de octubre y el 23 de marzo, fechas vinculadas a un pasado inmediato signado por la génesis de un movimiento que toma el poder y establece un Nuevo Orden en pocos años, se celebran con la misma regularidad y solemnidad que las fechas históricas de la Italia del Risorgimento. A pesar de que los acontecimientos evocados son recientes y no se trata de feriados nacionales, parecen haberse consagrado en un breve lapso con la misma firmeza que solo otorga el paso de las décadas.

La tercera transformación a destacar consiste en las relaciones de continuidad que establece L'Italiano entre las fechas que celebra. Según su interpretación, la fundación de los Fasci di Combatimento y la Marcha sobre Roma son una consecuencia de la Intervención y del triunfo de Vittorio Veneto, ya que responden al mismo espíritu de renovación nacional que hace de Italia una potencia victoriosa en la Primera Guerra Mundial. Por otra parte, la Marcha sobre Roma se presenta como una nueva manifestación de la fuerza histórica que ya se expresa en el Risorgimento, con la aprobación del Estatuto Albertino, y que inspira la marcha de las tropas italianas sobre la Roma de los Papas:

Sicuro interprete dello spirito del Risorgimento, il Regime non ha soste commemorative: ma raccoglie la consegna dei grande che fecero l'Italia una e l'avvia verso una sicura potenza, degna della sua storia millenaria. ${ }^{33}$

De este modo, 1848, 1870, 1915, 1918, 1919 y 1923 constituyen fechas que, según L'Italiano, deben rememorarse dentro del marco de un único desarrollo histórico: el que rescata a Italia de su fragmentación, la unifica, la hace victoriosa y la destina a transformar el mundo. Pero este

32 «Anniversario de la fondazione dei Fasci», L'Italiano, XIX, 868-869, 23-24 de marzo de 1929.

33 «La Festa dello Statuto», L'Italiano, XVII, 775, 5 de junio de 1927, 1. 
proceso no es más que la continuación de otro proceso milenario que surge con el nacimiento de la propia Roma:

\begin{abstract}
Dalla grande luce che si irradia da Roma annegano le ultime fiammelle dei due grande incendi che la degenerazione democrática appiccò a Parigi e a Mosca, la società umana scopre nel Fascio Littorio il segno della sua salvazione.

La ricorrenza del Natale di Roma — che il Duce ha consacrato a la festa del lavoroesalta e celebra le virtù civili italiane che concorrono volenterosamente alla rinascita e a la potenza della patria.

In Italia, patria eterna di tutte le patrie, infinite prove proclamano, ad orgoglio di tutti gli Italiani, la ripresa, la rivincita, storica di Roma e l'inizio, in suo nome, di una epoca nuova per la civiltà.

Quando la Patria degli Italiani aveva il nome di Roma il cittadino romano era signore del mondo. Quando la Patria cadde in servitù noi fummo emigranti. Credette un giorno il popolo nostro di trovar la salvezza nella ribellione universale, ma bestemmiò il nome di Italia e la sua causa fu dannata.

Con la guerra e con la vittoria, con la Marcia su Roma e nel segno del Littorio e delle Corporazione — simbolo di potenza e di capacità creativa — la Patria e risorta e il cittadino romano rivive nel cittadino fascista. ${ }^{34}$
\end{abstract}

La cita anterior sintetiza no solamente la resignificación de hechos celebrados como expresión de un proceso único, sino que además enuncia con claridad la interpretación fascista de la historia de Italia y de la propia historia de la Humanidad. Desde esta perspectiva, la «Patria itálica» nace con Roma, madre de la civilización y de sus valores universales. Cuando esa patria cae bajo el yugo extranjero, los «italianos» se diseminan por el mundo, llevando las luces de esa civilización. Luego, la tentación de la «degeneración democrática» se presenta, y los italianos que ceden a ella conducen a su patria al desastre. Entonces, se produce la regeneración salvadora: la intervención en la Primera Guerra Mundial, el triunfo de Vittorio Veneto y la Marcha sobre Roma, tres acontecimientos indisolublemente ligados. La salvación de Italia, entonces, es el comienzo de la salvación de la Humanidad, del mismo modo que el nacimiento de Roma es la génesis de la civilización universal. L'Italiano habla de «degeneración democrática» para aludir a la Revolución Francesa y a la Revolución Rusa. Aún no califica a la democracia como un sistema degenerativo, sobre todo porque es el sistema que impera en la sociedad receptora. Pero cuando la situación política uruguaya cambie en los años siguientes, la tónica de su discurso se exacerbará y no tendrá reparos en contraponer la democracia al fascismo:

34 «Il Natale di Roma», L'Italiano, XVIII, 820-821, 22-29 de abril de 1928, 1. 
la primera como una expresión decadente del pasado y el segundo como un régimen que transforma el presente y se proyecta hacia el futuro.

La cuarta transformación a analizar nace de una suerte de fusión por proximidad de fechas que responden a contextos históricos dispares. El 29 de octubre, el 4 de noviembre y el 11 de noviembre definen prácticamente dos semanas de festejos sin interrupción, que enfervorizan a los filofascistas de las colectividades ítalo-uruguayas de todo el país.

La quinta y última transformación consiste en la incorporación de la Era Fascista en las dataciones que utiliza L'Italiano. La Marcha sobre Roma se percibe, entonces, como el inicio de una nueva era a partir de la cual referir y computar los hechos. Por ello, el semanario reproduce en uno de sus números las medallas conmemorativas acuñadas por el gobierno de Mussolini para celebrar los «avances» alcanzados en cada uno de los primeros seis años de esa nueva era. ${ }^{35}$

Las cinco transformaciones mencionadas se hallan claramente documentadas en el plano discursivo. Resta por determinar qué acontece en el ámbito de las escenificaciones festivas. El estudio de los actos en que los ítalo-uruguayos celebran las efemérides de su madre patria solo es posible a través de representaciones mediáticas. La referencia a tales escenificaciones subsiste en el testimonio gráfico y textual de los periodistas ítalo-uruguayos que asisten y generan múltiples registros de esos eventos. Se conforman, así, dos escenarios: el original (que se corresponde con el de algunos teatros capitalinos y de ciertas entidades asociativas y culturales vinculadas con la colectividad inmigrante) y el hemerográfico (que nace de las fotografías y de los relatos publicados en L'Italiano, esencialmente). Emergen, al mismo tiempo, dos clases de escenificaciones: la primera, presencial, que no resulta directamente accesible al investigador; la segunda, mediática, que se constituye en registro y representación de la anterior. Esta última se convierte, además, en escenificación virtual que ejerce un efecto directo en el lector. Se configuran, entonces, dos clases de públicos: el que asiste a algunas de las escenificaciones referidas, y el de los lectores que se informan sobre los actos celebratorios a través de los artículos que dan noticia sobre ellos. Por lo tanto, el testimonio de la puesta en escena, es decir, la representación de la representación, deviene un factor significativo en la construcción colectiva de la percepción que tiene la comunidad ítalo-uruguaya filofascista de los actos conmemorativos propiamente dichos.

35 «I primi sei anni del Regime consacrate in sei artistiche medaglie», L'Italiano, XIX, 868-869, 23-24 de marzo de 1929, 3. 
Tres son las celebraciones que generan actos sociales de relevancia durante esos años: la fiesta del Natale di Roma, la fiesta que recuerda la unificación de Italia y la aprobación del Estatuto Albertino y la fiesta del 20 de septiembre. Tales actos se organizan en espacios diferenciados. El Natale di Roma, que suele celebrarse en el Teatro Stella d'Italia, congrega a un amplio público; durante las ceremonias se suceden los discursos de los representantes diplomáticos y de las autoridades de la Scuola Italiana, el recitado de textos literarios y la ejecución de un variado repertorio musical. ${ }^{36}$ Las fiestas relativas al Estatuto Albertino y al 20 de septiembre, ligadas a la Italia del Risorgimento, se desarrollan en otra clase de espacios, como el Club Italia ${ }^{37}$ o la propia Scuola Italiana. En esta última, las ceremonias suelen comenzar con el discurso del presidente de la institución educativa, continúan con el de alguna autoridad diplomática visitante y finalizan con la interpretación de la Marcha Real y de la Leyenda del Piave, a cargo del coro estudiantil. ${ }^{38}$

En lo que atañe a la celebración de los feriados nacionales uruguayos, se mantiene la misma impronta discursiva que en la fase previa. El 25 de agosto de 1927 L'Italiano reproduce el saludo del gobernador de Roma. Tanto en el título de la salutación como en su contenido, se exponen con claridad la interpretación del lazo histórico que une a ambas naciones:

La Grande Madre Roma, la Città Eterna, la Capitale dell'Italia di Vittorio Veneto e della Marcia Liberatrice, nella parola del suo Illustre Governatore Principe Ludovico Spada Potenziani invia nell'odierna celebrazione il suo messaggio d'amore all'Uruguay. [...] Roma, che sul tonante Vascello, visse una delle sue più belle epopee, Roma che aprì le materne braccia ai suoi Liberatori, e che in Giuseppe Garibaldi ebbe splendido precursore del Duce novissimo dell'Italia redenta, Roma inivia il suo commosso e riconoscente saluto a cotesta novile terra dove le orme del leonino Eroe dei due

36 «Il Natale di Roma nella "Dante" e nella Scuola», L'Italiano, XIII, 566, 29 de abril de $1923,3$.

37 «Echi del XX Settembre», L'Italiano, XIX, 896, 6 de octubre de 1929, 1.

38 «Scuola Italiana», L'Italiano, XII, 543, 12 de noviembre de 1922, 3. Las celebraciones referidas hasta el momento, algunas procedentes de la Italia del Risorgimento y otras incorporadas por la Italia fascista, combinan fiestas nacionales y fiestas consuetudinarias. A partir del calendario cívico que por ley aprueba el gobierno de Mussolini en 1930, la condición de muchas de ellas se modifica: (i) se elimina el 20 de septiembre como fiesta nacional y se mantiene el primer domingo de junio como fiesta de la unidad italiana y del Estatuto Albertino; (ii) se incorpora el 28 de octubre (Marcha sobre Roma) y el 4 de noviembre (aniversario de la victoria italiana de Vittorio Véneto) como feriados nacionales; (iii) se mantiene el 21 de abril (Natale di Roma y Festa del Lavoro) como jornada festiva; (iv) se consagran el 23 de marzo (fundación de los Fasci di Combatimento), 24 de mayo (intervención de Italia en la Primera Guerra Mundial) y el 11 de noviembre (natalicio del rey Vittorio Emanuel III) como solemnidades civiles. Véase «Elenco delle festività civili, militari e religiose», [en línea], http://www.indire.it/lucabas/ lkmw_file/archivio_storico/Elenco_festivita_civili_militari_religiose.pdf [Consultado: 15/09/2018]. 
Mondi splendono per sempre di purissima luce, intendono così prendere parte col suo cuore titánico e millenario, alla maggiore festa nazionale che celebra oggi il generoso Popolo dell'Uruguay. ${ }^{39}$

\section{Tiempos de aceptación: la glorificación del imperialismo fascista en el Uruguay dictatorial (1933-1938)}

El desarrollo de los acontecimientos políticos en el Uruguay de los años treinta introduce cambios significativos en la relación de los ítalo-uruguayos filofascistas con sus dos patrias. La crisis de 1929 impacta con fuerza en el Uruguay a partir de 1931, provocando un incremento de las tensiones socioeconómicas y políticas. En este contexto, el presidente Gabriel Terra encabeza un golpe de Estado en marzo de 1933 y establece un régimen dictatorial que recibe el respaldo de los sectores más conservadores del espectro político y social. ${ }^{40} \mathrm{El}$ gobierno de Terra demuestra una clara simpatía por la Italia de Mussolini. De hecho, las relaciones entre ambos países se estrechan con la llegada del conde Serafino Mazzolini, nuevo encargado de la Legación Italiana en el Uruguay. Durante el tiempo en que permanece en el país (fines de 1932 a principios de 1938) transforma la Legación en un centro propagandístico del fascismo en el Uruguay y logra que la mayoría de las entidades asociativas vinculadas con la comunidad migrante se sumen a sus propósitos. ${ }^{41}$ A partir de entonces, las celebraciones vinculadas con el fascismo, en particular el Natale di Roma, se conmemoran en el Auditorio del SODRE (Servicio Oficial de Radiodifusión Eléctrica) ${ }^{42}$ o en el Teatro Solís, ${ }^{43}$ principales salas de la capital uruguaya. Esas celebraciones (a las que Mazzolini asiste luciendo el uniforme de los Camicie Nere) conjugan discursos propagandísticos con presentaciones artísticas y musicales. Por el testimonio que brindan las fotografías que publica el semanario, tales eventos parecen convocar a un público numeroso que llena las salas.

En esos años, Mazzolini moviliza los recursos necesarios para lograr la ampliación del salón de actos de la Scuola Italiana. Cuando se reinaugura,

39 «Il Governatore di Roma», L'Italiano, XVII, 786-787, 21-28 de agosto de 1927, 1.

40 Véase Caetano y Jacob, 1990.

41 Oddone, 1997.

42 «La solenne commemorazione del Natale di Roma e della Festa del Lavoro in Montevideo», L'Italiano, XXVI, 1179, 5 de mayo de 1935, 5.

43 «La solenne commemorazione del Natale di Roma e della Festa del Lavoro in Montevideo. La premiazione degli alunni della Scuola Italiana-Il discorso commemorativo di S. E. il Ministro Mazzolini», L'Italiano, XXVIII, 1278-1280, 21 de abril-2 de mayo de 1937, 12. 
su uso ya no responde a los requerimientos exclusivos de las autoridades de la institución, sino a las exigencias de la Legación Italiana, que lo transforma en una herramienta propagandística formidable. La presencia del diplomático fascista en la Scuola motiva diversos actos que escenifican su poder dentro de la colectividad y su papel como representante de la Nueva Italia. En los actos festivos no solo se interpretan la Marcha Real y la Leyenda del Piave, sino que se ejecutan Giovinezza ${ }^{44}$ y el Himno de los Balilla. Además, Mazzolini logra que una delegación de docentes y de estudiantes de la Scuola participe en las fiestas patrióticas celebradas en los principales teatros montevideanos. ${ }^{45}$

El estallido de la Segunda Guerra Ítalo-Etíope (1935-1936) desata una campaña propagandística inédita, destinada a reclutar combatientes y a recabar oro y metales preciosos para financiar la contienda. ${ }^{46} \mathrm{Culminado}$ el conflicto con la anexión de Etiopía, nace entonces un efímero Imperio italiano (1936-1941), cuya fecha de fundación (9 de mayo) se conmemora a partir de 1937 en aparatosas ceremonias realizadas en el Teatro Solís, bajo la estricta supervisión de Mazzolini, primero, y luego bajo la de su sucesor, Alberto Bellardi Ricci. ${ }^{47}$ Las convocatorias de L'Italiano a celebrar el 9 de mayo trascienden al universo de la colectividad migrante, ya que consideran que esa fecha aúna a italianos y a uruguayos por igual:

A fianco degli italiano devono esere i loro figli e gli amici dell'Italia, deve essere tutta la progenie de la razza latina nell'Uruguay, perchè Roma è la culla immortale, è cristiana, è invincibile. Fra questi collaboratori cooperatori saldi, fedeli ricordiamo per prima la eroica coorte di italiani e loro figli da qui partita per andare a combattere nell'Africa.

Sui campi d'Africa, oggi italiani, il nome della collettività italiana nell'Uruguay ed il nome di questa generosa terra amica ed ospitale furono onorati da quei valorosi Legionari. ${ }^{48}$

El Día del Imperio motiva la aparición de nuevas alegorías en las páginas del semanario. Una en particular representa el territorio de Etiopía como un ala nacida de la efigie de Italia, que apoya uno de sus brazos

44 Giovinezza es una de las canciones más conocidas de la época fascista.

45 Véase nota 43.

46 «Elenco dei Volontari per l'Africa Orientale partiti da Montevideo», L'Italiano, XXVI, 1209-1210, 8-15 de diciembre de 1935, 2.

47 «La cellebrazione ufficiale della fondazione dell'Impero al Teatro Solís», L'Italiano, XXXI, 1371-1373, 20-28 de mayo de 1939, 2.

48 «La collettività italiana, i figli degli italiani e gli amici d'Italia nell'Uruguay per la conquista dell'Impero», L'Italiano, XXVIII, 1278-1280, 21 de abril-2 de mayo de 1937, 3. 
sobre los fascios lictorios mientras que con el otro sostiene la luz de la civilización (figura 6). La ilustración alude a dos fechas (la fundación de Roma y el primer aniversario de la fundación del Imperio), uniéndolas en un vínculo simbólico de identidad absoluta, incuestionada e incuestionable para una concepción que se muestra tan dogmática como esencialista. Alcanza, entonces, su expresión más pura el discurso imperial de la Tercera Roma: la primera es la Roma antigua de los Césares, la segunda es la Roma renacentista de los Papas, y la tercera es la Roma moderna del Duce y del régimen fascista.

En este contexto propicio para expresiones desembozadas de adhesión al fascismo, la celebración del Día de la Independencia uruguaya adquiere una particular significación, ya que el presidente Terra, al tiempo que elimina la mayor parte de los feriados establecidos por la ley de 1919, mantiene el 25 de agosto como el feriado nacional. Por ello, cada 25 de agosto L'Italiano publica una ilustración que reafirma la relevancia de esa fecha, recurriendo a una alegoría que simboliza los vínculos que unen a Italia y Uruguay: bajo el monumento a José Artigas — «el fundador de la nacionalidad uruguaya» en palabras del semanario- dos figuras femeninas (personificaciones de ambas patrias) caminan con sus manos entrelazadas (figura 7). Detrás de ellas, se despliega la partitura del himno nacional uruguayo, algunos de cuyos acordes se inspiran en ciertos fragmentos de la ópera Lucrezia Borgia de Gaetano Donizetti. En los aniversarios del 25 de agosto durante el gobierno de Terra, esta alegoría a veces se halla acompañada de una fotografía del presidente y de una carta de salutación al semanario. ${ }^{49}$

En los aniversarios del 25 de agosto, L'Italiano reafirma una idea central de su discurso: celebrar la existencia de un Uruguay independiente también es recordar las contribuciones de aquellos italianos que han dejado una huella visible en el progreso del país. Como ejemplo de ello refiere los nombres y las obras de tres figuras que resaltan ese estrecho vínculo. En tal sentido, recuerda a sus lectores que Angelo Zanelli es el creador del monumento a Artigas, emplazado en la Plaza Independencia de Montevideo e inaugurado en 1923. Menciona, además, que Caetano Moretti es el arquitecto que diseña el Palacio Legislativo. Finalmente, refiere que la Estación Central de ferrocarriles de Montevideo es obra de otro italiano, el

49 «S. E. il Presidente della Repubblica, avv. Grabiele Terra», L'Italiano, XXIV, 1142-1143, 19-31 de agosto de 1934, 1. 
Figura 6. Alegoría de la Italia imperial. L'Italiano, XXVIII, 1278-1280, 21 de abril2 de mayo de 1937, 1.

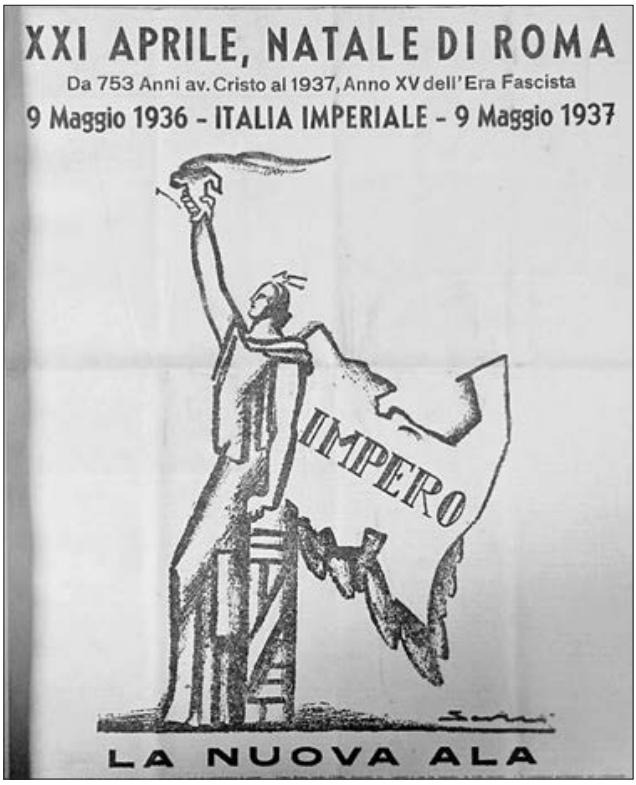

FIGURA 7. El 25 de agosto y la fraternidad ítalo-uruguaya. L'Italiano, XXII, 1039-1040, 21-28 de agosto de 1932, 1.

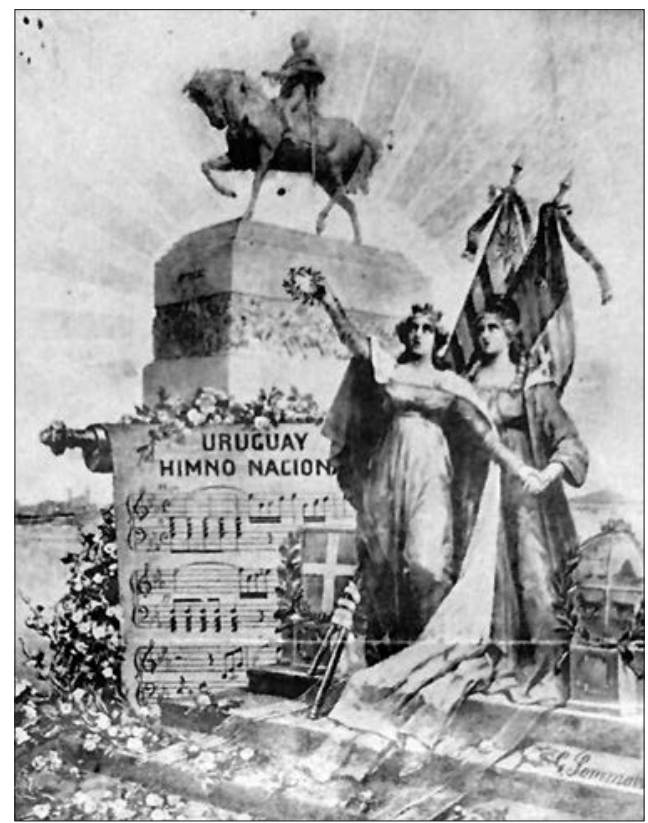


ingeniero Luigi Andreoni. ${ }^{50}$ Es decir, tres referentes urbanos característicos de Montevideo (el monumento a Artigas en la Plaza Independencia, el Palacio Legislativo y la Estación Central) se relacionan con los aportes de italianos destacados. El semanario también menciona el hecho de que el primer poblador de Montevideo es un «italiano». Giorgio Borghese (en español Jorge Burgues), hacendado y funcionario del gobierno colonial rioplatense, nacido en Génova, es considerado el primer poblador civil de San Felipe y Santiago de Montevideo. ${ }^{51} \mathrm{Si}$ bien Burgues es genovés y no italiano (ya que no existía el Reino de Italia en ese entonces), vincular su nombre con el aporte de una italianidad imaginada a la génesis de la ciudad que se convertiría en la capital del futuro Estado uruguayo tiene un efecto retórico audaz.

\section{Tiempos de repliegue: la defensa del gobierno de Mussolini en el Uruguay neutral (1939-1941)}

Con la culminación de la década del treinta, el régimen autoritario instaurado en Uruguay llega gradualmente a su fin. En 1938, Alfredo Baldomir asume la presidencia y a diferencia de Terra no desarrolla un vínculo estrecho con el gobierno de Mussolini. ${ }^{52}$ Por otra parte, en las vísperas de la Segunda Guerra Mundial, la proyección de las ideologías totalitarias en la sociedad uruguaya desata una inquietud generalizada con respecto a su «infiltración» en el ámbito educativo. ${ }^{53}$ Surgen entonces asociaciones y órganos de prensa en el seno de la propia colectividad ítalo-uruguaya que desatan una campaña antifascista. ${ }^{54}$ Cuando finalmente estalla la guerra, L'Italiano realiza esfuerzos denodados por demostrar la lealtad de sus simpatizantes hacia el gobierno uruguayo y hacia la sociedad que los ha recibido e integrado. Recurre a referencias históricas que demuestran el modo en que los italianos contribuyeron al desarrollo material y cultural del país y a su consolidación como Estado independiente. Sostiene, además, que los lazos que unen a Uruguay e Italia se manifiestan a través de las luchas históricas en las que italianos combatieron por Uruguay y los uruguayos lo hicieron por Italia. Por ello, ante las acusaciones de la existencia de una

50 Portada sin título, Ibidem, 1. 1937,7

51 «1825-XV Agosto-1937», L'Italiano, XXVIII, 1286-1288, 24 de mayo-6 de junio de

52 Véase Frega, Marona y Trochon, 1987.

53 Véase Frugoni,1938.

54 Véase Bresciano, 2009. 
quinta columna fascista en Uruguay que conspira en favor del gobierno de Mussolini, el semanario responde recordando a otra «columna»: la de los legionarios italianos caídos en el combate de Tres Cruces o en la batalla de San Antonio durante la Guerra Grande, que murieron en defensa de su país de adopción. ${ }^{55}$ También refiere la suerte de aquellos uruguayos que perecieron luchando por Italia. Entre los ejemplos más citados figura el de Andrés Aguiar, garibaldino que cayó en 1848 durante la defensa de Roma, y del hermano del presidente José Serrato, muerto en acción durante la Primera Guerra Mundial.

La evolución de los acontecimientos mundiales y locales ahonda las divisiones ideológicas en el seno de la comunidad ítalo-uruguaya a principios de los años cuarenta. En 1942, Baldomir lidera un golpe de Estado (el «golpe bueno») que supone el fin del terrorismo y el principio de la restauración democrática. ${ }^{56} \mathrm{Su}$ gobierno, al igual que los de la inmensa mayoría de los países latinoamericanos, rompe relaciones diplomáticas con las potencias del Eje. En 1943, con la asunción de Juan José de Amézaga como presidente, el país se orienta claramente hacia el bloque aliado. Se consolida así un nuevo contexto histórico en el que la gravitación del fascismo se desvanece de forma acelerada, al tiempo que surgen nuevas organizaciones que luchan por la reconstrucción de una Italia democrática. Para ese entonces, en la comunidad ítalo-uruguaya el apoyo público al gobierno de Mussolini se había diluido por completo.

\section{Conclusiones}

En el transcurso de dos décadas, las conmemoraciones patrióticas de los ítalo-uruguayos filofascistas experimentan transformaciones que dan cuenta de las dinámicas político-ideológicas que afectan a Uruguay, a Italia y al mundo durante el período interbélico. No solo se modifican las efemérides de ambos países (por incorporaciones y supresiones sucesivas) sino que además se resignifican. Esas resignificaciones motivan un discurso específico sobre las relaciones entre presente y pasado, generan actos celebratorios que obedecen a tipologías cambiantes, y en algunas ocasiones

55 Da Locri, Guglielmo, «La Nostra “Quinta Colonna”», L'Italiano, XXXI, 1426, 24 de mayo de 1940, s.p.

56 Véase Frega, Marona y Trochon, 1987. 
producen alegorías iconográficas cuyo simbolismo revela un conjunto ingenioso de estrategias comunicativas.

En lo que atañe a las relaciones entre presente y pasado, debe destacarse la conmemoración de hechos recientes de la historia italiana. Su inclusión propicia, por una parte, una relectura de acontecimientos fundacionales del siglo XIX, mientras que, por la otra, suscita una reinterpretación de desarrollos civilizatorios que se remontan a la Antigüedad clásica. La tendencia a sumar hechos de un pasado inmediato se acentúa durante el período estudiado: primero se incorporan las efemérides relativas a la Primera Guerra Mundial, luego las que se vinculan a la instauración del régimen fascista y por último la que consagra la fundación del (fugaz) Imperio de la Tercera Roma. Todas ellas introducen nuevas valoraciones retrospectivas del pasado italiano, en razón de los fundamentos doctrinarios del fascismo.

La celebración de hechos que corresponden al pasado de la sociedad de procedencia se conjuga con la rememoración de los acontecimientos históricos que festeja la sociedad de recepción. Los cambios políticos dispares que afectan a ambas generan un discurso que busca conciliar las divergencias y potenciar las convergencias. Estas divergencias y convergencias se alternan significativamente durante las fases del período: en los años veinte, mientras que en Uruguay se consolida un régimen democrático, en Italia se impone una dictadura que sienta las bases de un Estado totalitario; a partir de 1933, en Uruguay se instaura una dictadura que expresa su simpatía por la Italia fascista en su apogeo; por último, a fines de la década de los treinta, en Uruguay se inicia una transición hacia la democracia mientras que Italia sella su alianza con la Alemania nazi.

El discurso integrador que aspira a armonizar el sentido de las fiestas cívicas de ambos países, se hace eco de esas alternancias con estrategias retóricas que buscan diluir, simbólicamente, las divergencias cuando estas últimas resultan manifiestas. Tal discurso se repite con insistencia en los actos públicos celebratorios y se refleja también en un conjunto de alegorías iconográficas que, publicadas en las páginas de L'Italiano, sintetizan visualmente una «imaginada» unidad de principios y de propósitos, de pasados y de futuros entre ambas naciones. Pero todo el esfuerzo termina siendo vano cuando la ruptura de relaciones diplomáticas entre Uruguay y las potencias del Eje hace imposible cualquier conciliación.

Recibido el 16 de octubre de 2018

Aceptado el 9 de enero de 2019 


\section{Referencias bibliográficas}

Adamo, Gianfranco, Facetas históricas de la emigración italiana al Uruguay, Montevideo, Tall. Gráf. EMBA, 1999.

Aróstegui, Julio, La historia vivida. Sobre la historia del presente, Madrid, Alianza Editorial, 2004.

Bresciano, Juan Andrés, «El antifascismo ítalo-uruguayo en el contexto de la Segunda Guerra Mundial», DEP. Deportate, esuli, profughe, 11, 2009, 94-111, https://www.unive.it/media/allegato/dep/Dep_11_2009.pdf.

Bresciano, Juan Andrés, «La Tercera Roma en el Río de la Plata. El fascismo y su difusión en la colectividad ítalo-uruguaya», en Cappelli, Vittorio y Sergi, Pantaleone (eds.), Traiettorie culturali tra il Mediterraneo e l'America latina. Cronache, letterature, arti, lingue e culture, Cosenza, Pellegrini, 2016, 239-256.

Bresciano, Juan Andrés, «La Scuola Italiana di Montevideo davanti agli impeti del fascismo. Dalla resistenza alla resa (1922-1942)», Giornale di Storia Contemporanea, XXI, 2, Cosenza, 2017, 25-42.

Caetano, Gerardo y Jacob, Raúl, El nacimiento del terrismo (1930-1933), Montevideo, Ediciones de la Banda Oriental, 1990, tomo 1.

Caetano, Gerardo y Geymonat, Roger, La secularización uruguaya (1859-1919), Montevideo, Santillana, 1997.

Devoto, Fernando et al., L'emigrazione italiana e la formazione dell'Uruguay moderno, Turín, Edizioni della Fondazione Giovanni Agnelli, 1993.

Domínguez Méndez, Rubén, «Dos instrumentos en la propaganda exterior del fascismo: emigración y cultura», Hispania Nova. Revista de Historia Contemporánea, 10, 2012, http://hispanianova.rediris.es/10/articulos/10a009.pdf.

Franzina, Emilio y Sanfilippo, Matteo, Il fascismo e gli emigrati. La parabola dei Fasci italiani all'estero (1920-1943), Bari, Editore Laterza, 2003.

Frega, Ana; Marona, Mónica y Trochon, Yvette, Baldomir y la restauración democrática, Montevideo, Ediciones de la Banda Oriental, 1987.

Frugoni, Emilio, El nazi-fascismo en la enseñanza, Montevideo, Oficina de la C. Pro Congreso de Periodistas Libres, 1938.

Lowenthal, David, El pasado es un país extraño, Madrid, Akal, 1998.

Oddone, Juan Antonio, «Serafino Mazzolini un misionario del fascismo en Uruguay, 1933-1937», Estudios Migratorios Latinoamericanos, 12, 37, 1997, 375-388.

Real de Azúa, Carlos, Los orígenes de la nacionalidad uruguaya, Montevideo, Arca, 1990.

Sergi, Pantaleone, Storia de la stampa italiana in Uruguay, Montevideo, Fondazione Italia nelle Americhe, 2014. 